EPiC Series in Computing
Volume 78, 2021, Pages 1-8
Proceedings of the European Univer-
sity Information Systems Conference 2021

\title{
A new Digital Innovation Model for Higher Education after the Covid-19 Pandemic
}

\author{
Pekka Kähkipuro ${ }^{1}$ \\ ${ }^{1}$ Brunel University London, UK, Orcid: 0000-0003-4130-9322 \\ Pekka.Kahkipuro@tuni.fi
}

\begin{abstract}
Digital innovation is a significant source of business and operational improvements in almost all sectors. The progress of digital transformation and the response to the Covid19 pandemic have changed the role of digital innovation in the Higher Education sector as well. Digital innovation has moved from the fringes of the business to the core. This paper describes the changes that are taking place and the underlying dynamics of those changes. We also describe how the digital innovation process needs to be updated to accommodate the new requirements and to meet the new expectations.
\end{abstract}

\section{Background}

Digital technologies have been a source of innovations in most organisations for years. Digital transformation refers to the business changes information technology can bring to the organisation. Higher education is no exception, and digital innovations have been used to boost the business in many ways (Kähkipuro, 2015, 2017). Typical models for managing and exploiting innovations have been discussed in the literature, see Davila, Epstein \& Shelton (2006) for a good overview. These models have been working well in managing digital innovation in the context of traditional higher education work.

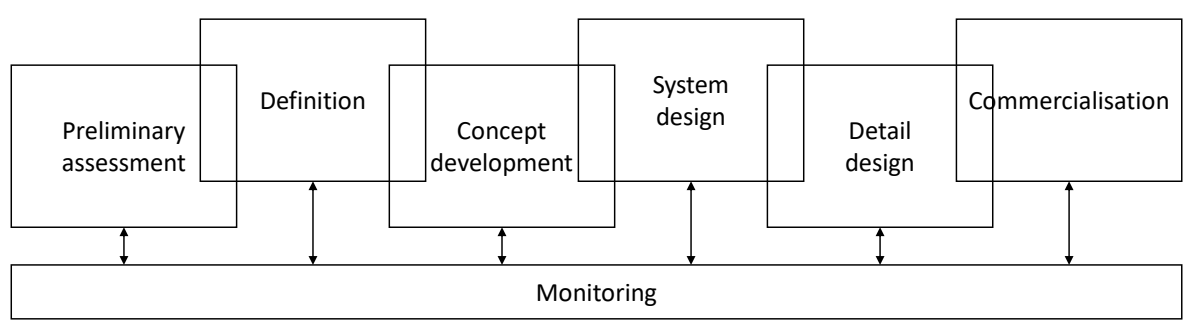

Figure 1. Traditional process for digital innovation. 
The process for creating digital innovations is well understood, and several models have been presented to drive the commercialisation of initial ideas discovered through the pipeline. Figure 1 illustrates a typical digital innovation process (Hellwig, Pawlowski \& Schäfer, 2020).

However, we have recently experienced two significant changes that have altered the landscape. Firstly, digital transformation has enabled organisations to radically change their core business. This has changed the role of digital innovation from the fringes of the organisation to the core of it in Higher Education. A good example is the introduction of online programmes to replace traditional ones. Secondly, the Covid-19 has created an unprecedented disruption in the need for digital support for business, as traditional campus-based activities have been suspended or reduced significantly.

\section{What happened in response to the pandemic?}

When the pandemic hit the higher education sector in early 2020, three significant changes took place in most institutions. Firstly, there was a swift migration to online teaching with an immediate introduction of new working practices, new ways of using existing tools, and new tools to support previously uncovered needs. The change was visible in all activities, including teaching and learning, research, administrative work, assessments, attendance monitoring, student support, etc.

Secondly, organisations turned into remote working practices in their internal activities. Most professional services either transformed their service models into remote mode (e.g., changing face-toface student and staff interactions into online services) or introduced entirely new ways of dealing with the requirements (e.g., using external service partners).

The third significant change took place once it was clear that partial restrictions would be present for a significant period even if the immediate peak of restrictions had been passed. This introduced the need for mixed mode operations in all areas. In teaching and learning, traditional blended learning practices are now being extended with new teaching models, such teaching events with both remote and face-to-face students in the same session. Likewise, meeting practices are being introduced to support arrangements where remote participants are interacting with participants in one or more physical meetings. Existing processes and practices are being extended to support both on-site and online participation in parallel, and this change is still ongoing.

The most extraordinary change, though, was the ability for most institutions to implement the above three steps in a very short time and with a high level of efficiency. This seems contradictory to the traditional conservative mindset and slow adoption rate of new practices in the Higher Education sector. To understand how this was possible, it is important to analyse the innovation model behind these changes. In the following sections, we shall investigate how the new model differs from the traditional one, and how it works in practice.

\section{Key differences from the traditional innovation model}

To understand how recent innovations are different from the traditional approach, we are using the seven innovation rules presented by Davila, et al. (2006). Figure 2 illustrates the main differences between exiting practices and the new model that is gradually been adopted by HE institutions.

The essential change between the models is the closeness of innovation to the core business education and research. Previously, the core was relying on traditional practices and taking digital technologies into use at a relatively slow pace through incremental innovation. Radical innovation was mainly operating at the fringes of the core business and, consequently, there was lack of management focus and less support from the wider community. 


\begin{tabular}{l|l|l|}
\hline Rule & Traditional HE approach & New model \\
\hline $\begin{array}{l}\text { 1. Strong leadership and clear } \\
\text { direction from the top }\end{array}$ & $\begin{array}{l}\text { Large number of initiatives and } \\
\text { evenly spread resources }\end{array}$ & $\begin{array}{l}\text { Focused approach to secure } \\
\text { business continuity }\end{array}$ \\
\hline $\begin{array}{l}\text { 2. Integrate innovation with the } \\
\text { basic business mentality }\end{array}$ & $\begin{array}{l}\text { Innovation operating on the fringes } \\
\text { but less so on the core business }\end{array}$ & $\begin{array}{l}\text { Innovation addressing needs of the } \\
\text { core business: teaching/research }\end{array}$ \\
\hline $\begin{array}{l}\text { 3. Align the amount and type of } \\
\text { innovation with the business }\end{array}$ & $\begin{array}{l}\text { Innovation targeted for } \\
\text { experimental improvements }\end{array}$ & $\begin{array}{l}\text { Innovation targeted to secure/grow } \\
\text { the volume of main business }\end{array}$ \\
\hline $\begin{array}{l}\text { 4. Manage the tension between } \\
\text { creativity and value capture }\end{array}$ & $\begin{array}{l}\text { Creativity, diversity, and collegiality } \\
\text { high in value }\end{array}$ & $\begin{array}{l}\text { Ability to improve/maintain } \\
\text { education/research high in value }\end{array}$ \\
\hline $\begin{array}{l}\text { 5. Neutralise organisational } \\
\text { antibodies }\end{array}$ & $\begin{array}{l}\text { Slow progress is okay, there is no of } \\
\text { sense of urgency }\end{array}$ & $\begin{array}{l}\text { Pressure from core business } \\
\text { ensures traction }\end{array}$ \\
\hline $\begin{array}{l}\text { 6. Recognise the need for network } \\
\text { of people and knowledge }\end{array}$ & $\begin{array}{l}\text { Innovation through initiatives } \\
\text { driven by single individuals/units }\end{array}$ & $\begin{array}{l}\text { Sense of urgency increases } \\
\text { networking and partnering }\end{array}$ \\
\hline $\begin{array}{l}\text { 7. Create right metrics and rewards } \\
\text { for innovation }\end{array}$ & $\begin{array}{l}\text { Typical metrics: number of } \\
\text { initiatives, patents, and papers }\end{array}$ & $\begin{array}{l}\text { Core business metrics become the } \\
\text { measure of innovation }\end{array}$ \\
\hline
\end{tabular}

Figure 2. Key differences between the traditional and the new digital innovation models.

In the new model, innovation is aiming at radical or semi-radical ${ }^{*}$ changes in the core business to ensure that it can survive and thrive in the changing circumstances. This draws the attention of the institutional leaders and changes the dynamics in many other ways as indicated by Figure 2.

The first rule is about strong leadership and clear direction from the top. We are seeing how institutional leaders are changing their approach to using digital technologies. Previously, digital tools were used for enhancing traditional ways of working and for creating marginal extensions to the mainstream business, e.g., online courses with limited scope or MOOCs for marketing purposes. This scattered digital investments into several small bets across the board and, consequently, the impact was only limited. Going forward, and especially after the pandemic, digital tools are understood to be critical for delivering the mainstream business and this will increase the interest of the top leaders in the topic. In some cases, businesses or delivery models that were considered marginal will become part of the mainstream.

Example 1. Competing with online programmes. In the past, most Higher Education organisation have considered online programmes as peripheral fluctuations of the core business. The recent Covid-19 experiences have demonstrated that well implemented online programmes are a genuine competitor to the traditional education delivery and, consequently, there has been an increase in student numbers. As a result, this has turned the eyes of the institutional leaders to the online business itself and to changing traditional delivery into a dual mode model to provide superior student experience combining the benefits of both worlds.

The second rule is about integrating innovation with the basic business mentality. The impact of digital thinking is now extending into the wider organisation. Traditionally, digital innovation has been the diversion of a small group of academics. Mainstream education and research have been following well-known traditions with small stepwise changes with the availability of new digital tools. Lectures and "chalk and talk" have often remained the main delivery model even when other means have been available. Recent events have forced lecturers and researchers to look for new ways of achieving their professional goals. Consequently, digital innovation has started to be part of the basic business mentality and most improvement activities will consider the use of new digital solutions before looking at more traditional approaches.

\footnotetext{
* Radical innovation refers to a change where both the business model and the underlying technology are new. Semi-radial innovation refers to a change where only one of them is new.
} 
Example 2. Digital First. Brunel University London have adopted the "Digital First" principle in their digital strategy. While this may sound trivial, it creates a significant change in future improvements for working practices. Whatever new implementations are being planned, the initial step is to consider a digital approach first. This will ensure that the solution is future-proof and is potentially part of a future digital workflow lending itself to automation and self-service at a later stage. The traditional approach would have been an improved manual process with possible digitalisation in the longer run - leaving often clumsy manual steps in the process to be ironed out in the future.

The third rule is about aligning the amount and type of innovation with the business. The majority of digital innovation is now being pushed from experimentation into the core business. For some institutions, this may become an issue if digital transformation has spawned experimental niche projects where the focus has been in exploring new territories and not in creating new business. A possible solution is to implement a stepwise transition by starting all new digital projects with a clear business goal and a business-driven governance. This will gradually turn the plans and the mindset into securing and growing the mainstream business.

The fourth rule is about managing the tension between creativity and value capture. We have seen a change of attitude towards creating business value. In the traditional model, digital innovation has been part of the exploratory domain and, consequently, the way initiatives have been assessed has been based on traditional principles. Organisations have been valuing creativity over business impact, appreciating diversity over focused results, and rating collegiality over target-driven delivery. While both ends of the scale are still important, there is clearly a shift in emphasising business value - typically in the mainstream education and research - and pushing the balance towards that end. This will be visible in both decision-making and in the organisational rhetoric.

The fifth rule is about neutralising organisational antibodies. In most organisations, there is a natural resistance to change. As digital innovation has been targeting marginal parts of the business, the approach to address opposition in the digital domain has typically been a soft one. Often, the use of digital tools and practices has only been adopted on a voluntary basis. With the Covid-19 pandemic, there was no choice. To be able to work efficiently, new digital practices are typically the only available option. This in turn has paved the way for the mainstream organisation to strengthen its support for digital innovations and for clearing the resistance with stronger and more efficient measures. The carrot is probably still the preferred approach, but the stick is now being used as well.

The sixth rule refers to recognising the need for the networking of people and for the sharing of knowledge. The behaviour of digital practitioners is clearly changing. In the new situation, proponents of digital technologies and innovation are actively seeking likeminded colleagues to form networks and to share ideas. This is possible due to the wider recognition of the usefulness and desirability of digital practices for the sector. This networking is further accelerated and supported in most organisations through various initiatives, such as "digital roadmaps" or "digital visions". These initiatives often span across institutions and national borderlines. While such cross-organisational activities have existed for a long time, it seems that they are becoming increasingly popular as digital practices enter the mainstream of higher education.

Example 3. Cross-institutional digital initiatives. These initiatives operate at several layers. Firstly, there are focused cross-organisational initiatives where several institutions share a common problem and team up to solve it with a joint approach. A good example is the Jisc learning analytics initiative that initially created a conceptual framework to tackle the challenge and has later turned into a service provided by Jisc to its members (Ferrell, Smith \& Knight, 2018). The second type is represented by national initiatives for addressing a set of digital challenges for the entire sector. An example of this is the Finnish Digivision 2030 project to bring greater opportunities for all learners 
to learn flexibly (Nordlund, 2021). Such initiatives are typically using public funding and involve external organisations, ministries, etc. Finally, there are wider international digital initiatives that aim at solving challenges common to the sector independent of the country or context. The EUNIS special interest groups represent a good example of this category. Currently, there are eight groups ranging from learning and teaching to student mobility and AV/VR technologies. While all these initiatives are promoting the networking of people and the sharing of information, the future will tell which initiatives will be the most successful in terms of business value.

The last rule is about creating the right metrics and rewards for innovation. Again, we are seeing a shift of focus in the institutional metrics. In the new world, digital innovation is being measured through its direct impact on business. Depending on the institution and the funding model, this may the student income, efficiency in educational outcomes, efficiency in administrative work, or something similar. This is very different from the traditional metrics where the focus was on activities rather than on the results. Typical traditional metrics would have been the number of digital initiatives or the amount of funding obtained.

\section{Implications to the innovation process}

As discussed above, innovation activities are now driven by new requirements and this also changes the innovation process significantly. Unlike the traditional process in Figure 1, the new process starts from the expected outcome - this is typically a pressing business need or an experienced sense of urgency. The process also includes several iterative evaluation steps and possibilities of redesigning the tentative solution and tracing back to previous stages. An overview of the new process is illustrated in Figure 3. The iterative nature of the work in all stages is indicated by the circular arrows in the diagram.

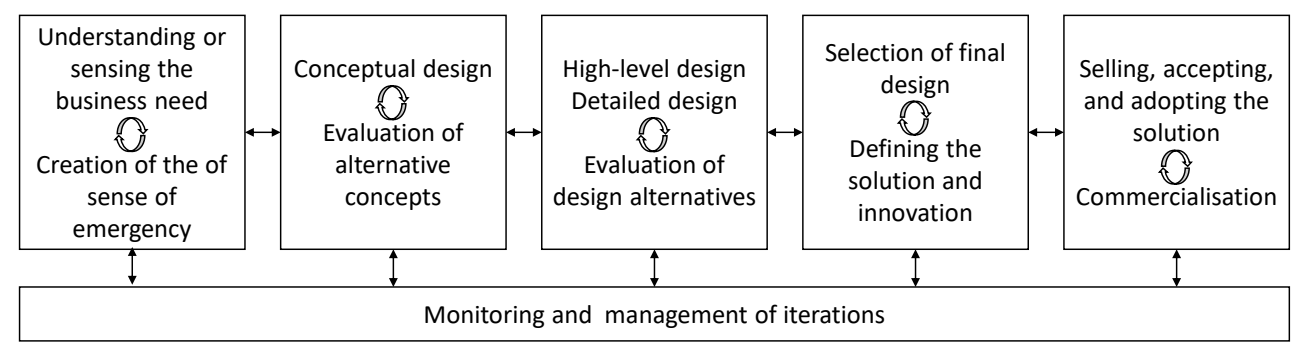

Figure 3. New process for digital innovation.

The assessment phase in the beginning of the process has typically two interrelated elements. On one hand, there is typically a business need which, to understand it in full detail, needs to be analysed and clarified. At the same time, the size of the issue and the actual need for the solution must be quantified from the business perspective. In parallel, this may involve the creation of a sense of urgency at the decision-making level of the organisation, making an effective way of linking the preparations of the innovation with the related business development activities. These two activities need to proceed in parallel and there is a fair amount of interaction between them.

Once the assessment has been completed and the business need has been identified as a genuine one, the actual concept of the innovation needs to be defined in full detail. Given the number of digital technologies available and the wide variety of available working practices in the higher education sector, there are typically multiple alternative options available. In a well driven process, you would expect several alternative concepts to be outlined and evaluated before moving forward in the workflow. 
In the conceptual phase, the main business risks and benefits are also being addressed and this effectively creates a business case for the project. Given the iterative nature of the process, the business case will be revisited in the fourth stage of the process during the final decision-making.

The design phase follows traditional iterative design practices. The existence of alternative digital technologies and alternative implementation choices withing a selected technology will often require several iterations to find the best solution. There is also an interplay between the high-level design and the detailed design. The former will indicate how well the design addresses the business concept, but it is the latter where the actual implications can be evaluated against various criteria, such as compatibility with the enterprise architecture, limitations imposed by cyber security, and data privacy requirements. Multiple iterations are often needed to find the optimal design.

In most institutions, the governance model requires an explicit decision-making phase to move ahead to the actual implementation. The obvious element is to approve the final design and the business case, but there are typically additional considerations. It is often at this stage when the scope of work and the actual innovation will be defined. Until this point, there may have been several possible avenues that could have been addressed with the selected technology, and critical thinking at both business and technical levels is required to ensure that the solution is what the organisation genuinely needs. There may be a need to look at the wider picture to understand what other initiatives are underway and how they are using organisational resources to address the identified business needs. Perhaps the selected solution does not have to solve everything that is within the reach of the chosen technology, or perhaps there is a gap in the requirements, and it needs to be added to the scope due to business urgency. Such considerations will change the remit of the final implementation.

The commercialisation phase typically moves forward in parallel with the implementation work. This phase will typically require additional work for engaging with the organisation to sell the selected solution, to adjust working practices, to realise potential benefits, and to set up the ongoing business model going forward. In this phase there is a need to do iterative work to shape the organisation and the innovation so that they can together address the business need in the best possible way. When the actual implementation gets closer to going live, the understanding in the user community also grows. This typically changes the nature of the dialogue and may change the way the innovation is perceived in the organisation. Hence the definition of the innovation in the business context may also change.

Example 4. Accessing engineering applications. When supporting the need for engineering students to use resource intensive applications in their studies, the traditional approach has been to build dedicated PC labs with high-end PC hardware and the required software. In addition, institutions often have difficulties in balancing the use of teaching spaces and, consequently, there is a constant need to move PC lab capacity around. In the beginning of the Covid-19 pandemic, Brunel University was faced with an interesting challenge where, in parallel, there was a sudden drop in the PC lab capacity and there was a need to access engineering applications remotely on a wider scale. Both issues were critical for delivering the business.

After several iterations, a solution was identified to address both challenges: the WMware Horizon software would be used for providing remote access capability and an integrated Virtual Desktop Infrastructure was to be implemented for providing the required additional desktop capacity. While the dialogue initially started from the PC lab capacity, it has turned out that the most important element of the innovation is the remote access capability. The solution itself is scalable in both dimensions, and the usage of the solution has later defined what the innovation means for the business.

In the proposed model, there are several process-wide elements to consider, and this is indicated by the wider box at the bottom of Figure 3. Firstly, there is typically toing and froing between the stages. This may even mean jumping back several stages in the process if, say, the business requirements 
change significantly. This is the direct consequence of the new process being more tightly connected to the business target setting - the process needs to be more sensitive to the changes in the wider context.

Secondly, most organisations are running a stage-gate governance model for their projects. This typically involves separate stages and gates for initiating the work, for approving the business case, for approving the project plan, etc. For the innovation model to be successful, it needs to be aligned with the existing organisational practices and this may obviously change some of the stages in the proposed model. This is particularly important for ensuring the availability of resources for the innovation work at various stages.

Thirdly, individual innovations are typically part of a wider pipeline and some of the decisions are influenced by factors that are outside the progress of a single innovation. As the new model is closer to the business, the management of the interaction of several parallel innovation processes becomes more critical from the business perspective. Element such as timing requirements and the need to optimise the use of resources come into play. Consequently, the wider pipeline management process becomes an important factor for individual innovations, and this may change the scope of work, the concept itself, and the implementation timeline.

Finally, since the new digital innovation model is increasingly addressing business relevant matters, the wider business context is also influencing the process. The innovation work cannot proceed in isolation of the institution's other business development activities. For the innovators, this may appear as an unnecessary intervention by the management, but this is what ensures that the innovations are genuinely driving the business forward, i.e., fulfilling the new role of digital innovation within higher education.

\section{Conclusion}

The role of digital innovation in higher education is changing radically. There are several reasons for the change. Firstly, the progress of digital transformation has increased the dependency of the business on digital tools and processes. In addition, several long-term changes such as the emergence of MOOCs, the growing popularity of online programmes, and the success of blended learning have gradually pushed digital innovation to the forefront in most institutions. Recently, the Covid-19 pandemic has forced organisations to change their working practices from physical to digital in a radical way. Together, these factors have created an entirely new digital innovation practice in several higher education institutions.

Consequently, innovation practices have moved from the outer edge of the HE business to the core. This has increased the attention of the top management and has changed the nature of the digital innovation work. As a result, the innovation process is being updated to accommodate new requirements and to meet new expectations. The proposed new approach starts from the expected outcome by exploring the business requirement and by understanding the need for change.

In this paper, we have provided an overview of the news process and we have compared it with the traditional approach. This comparison shows that the fundamentals behind innovation have changed significantly. In addition, we have described a process blueprint that can be used to implement the innovation model in an institution. The model is based on five iterative stages that enable the required tighter integration with business goals and value creation.

In the future, there are several questions that need to be investigated further. Firstly, it will be interesting to see how successful and sustainable this change is going to be in the higher education sector. The sector is often following conservative practices, and Covid-19 response may prove to be just a temporary quirk. Secondly, the proposed innovation model may have implications to the way IT organisations will be structured and this may have longer-lasting consequences in the progress of digital 
transformation in the sector. Thirdly, it will be interesting to see how the HE sector compares to similar changes that are happening in other sectors.

\section{Author biographies}

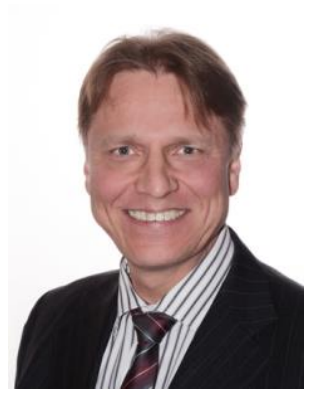

Pekka Kähkipuro is Chief Information Officer at Brunel University London where he is heading the Information Services Directorate. Prior to joining Brunel, Pekka was Director of IT at Aalto University in Finland in 2010-2016 and, before that, he held various senior roles in the private sector including Nokia. He has been a EUNIS board member on two occasions (2011-2015, 2018 onwards) and President in 2015. Pekka obtained his Ph.D. in computer science from the University of Helsinki in 2000 . He is a Fellow of the British Computer Society.

\section{References}

Davila, T., Epstein, M. J., Shelton, R. (2006). Making Innovation Work, How to Manage It, Measure It, and Profit from It. Upper Saddle River, NJ: Pearson Education.

Ferrell, G., Smith, R., Knight, S. (2018). Designing learning and assessment in a digital age. Jisc. https://www.jisc.ac.uk/guides/designing-learning-and-assessment-in-a-digital-age/learning-analytics

Hellwig, L., Pawlowski, J., Schäfer, M. (2020). An Innovation Activity Framework for Digital Innovation. In SIGMIS-CPR'20: Proceedings of the 2020 on Computers and People Research Conference (pp. 10-19). New York, NY: Association for Computing Machinery

Kähkipuro, P. (2015). Case Aalto University - Digital Transformation in Higher Education. In Collin, Hiekkanen, Korhonen, Halén, Itälä, Helenius (eds.), IT Leadership in Transition, The Impact of Digitalization in Finnish Organizations. Aalto University publication series, SCIENCE + TECHNOLOGY 7/2015, 81-88.

Kähkipuro, P. (2017). Essential IT capabilities for a successful digital transformation in Higher Education. European Journal of Higher Education IT 2017-1. EUNIS.

Nordlund, H., (2021). Higher Education Institutes' Digivision 2030. Finland as a model country for flexible learning. Arene, Unifi. https://digivisio2030.fi/wp-content/uploads/HEI-Digivision-2030.pdf 